\title{
Forced heat loss from body surface reduces heat flow to body surface
}

\section{A. Berman ${ }^{1}$}

Department of Animal Science, Hebrew University, Rehovot 76100, Israel

\section{ABSTRACT}

Heat stress is commonly relieved by forced evaporation from body surfaces. The mode of heat stress relief by heat extraction from the periphery is not clear, although it reduces rectal temperature. Radiant surface temperature (Ts) of the right half of the body surface was examined by thermovision in 4 lactating Holstein cows $(30 \mathrm{~kg}$ of milk/d) during 7 repeated cycles of forced evaporation created by $30 \mathrm{~s}$ of wetting followed by $4.5 \mathrm{~min}$ of forced airflow. Wetting was performed by an array of sprinklers $\left(0.76 \mathrm{~m}^{3} / \mathrm{h}\right)$, and forced airflow ( $>3 \mathrm{~m} / \mathrm{s}$ velocity) over the right side of the body surface was produced by fans mounted at a height of 3 $\mathrm{m}$ above the ground. Sprinkling wetted the hind legs, rump, and chest, but not the lower abdomen side, front legs, or neck. The animals were maintained in shade at an air temperature of $28^{\circ} \mathrm{C}$ and relative humidity of $47 \%$. Coat thickness was 1 to $2 \mathrm{~mm}$, so Ts closely represented skin temperature. Mean Ts of $5 \times 20 \mathrm{~cm}$ areas on the upper and lower hind and front legs, rump, chest, abdomen side, and neck were obtained by converting to temperature their respective gray intensity in single frames obtained at 10-s intervals. Little change occurred in Ts during the first wetting $\left(0.1 \pm 0.6^{\circ} \mathrm{C}\right)$, but it decreased rapidly thereafter $\left(1.6 \pm 0.6^{\circ} \mathrm{C}\right.$ in the fifth wetting). The Ts also decreased, to a smaller extent, in areas that remained dry $\left(0.7 \pm 1.0^{\circ} \mathrm{C}\right)$. In all body sites, a plateau in Ts was reached by 2 min after wetting. The difference between dry and wet areas in the first cooling cycle was approximately $1.2^{\circ} \mathrm{C}$. The Ts of different body areas decreased during consecutive cooling cycles and reached a plateau by 3 cooling cycles in dry sites (front leg, neck, abdomen side), by 5 cooling cycles in the hind leg, and 7 cooling cycles in the rump and chest. The reduction in mean Ts produced by 7 cycles was 4.0 to $6.0^{\circ} \mathrm{C}$ in wetted areas and 1.6 to $3.7^{\circ} \mathrm{C}$ in sites that were not wetted. Initial rectal temperature was $38.9 \pm 0.1^{\circ} \mathrm{C}$; it remained unchanged during first 5 cooling cycles, decreased by $0.1^{\circ} \mathrm{C}$ after 7 cooling cycles, and decreased to $38.4 \pm 0.06^{\circ} \mathrm{C}$ after 8 to 10 cooling cycles, with no additional subsequent decrease.

Received July 30, 2009.

Accepted September 29, 2009.

${ }^{1}$ Corresponding author: berman@agri.huji.ac.il
The concomitant reduction in Ts in dry and wet areas suggests an immediate vasoconstrictor response associated with heat extraction and later development of a cooler body shell. The reduction in rectal temperature represents a response involving transfer of heat from the body core to the body shell. This response mode requires consideration in settings of heat stress relief.

Key words: heat stress relief, heat extraction, vasoconstriction

\section{INTRODUCTION}

Relief of heat stress has been examined from a variety of perspectives. In hot, dry environments, evaporative cooling of confined, shaded environments was effective in reducing stress of ambient temperature (Armstrong et al., 1985), but its effectiveness decreased in more humid climates (Brown et al., 1974). The effect of ambient humidity on the expected reduction in ambient temperature has been quantitatively defined (Berman, 2009). Enhancing convective heat loss by 1 to $1.5 \mathrm{~m} / \mathrm{s}$ of airflow may extend use of evaporative cooling into less-dry conditions when relative humidity in the cooled ambience does not exceed 75\% (Berman, 2006). Repeated, thorough wetting of the hair coat at 5-min intervals coupled with forced airflow extracted heat from the body surface and was indicated for heat stress relief that was not affected by ambient humidity (Flamenbaum et al., 1984, 1986). Integrating this procedure into the farming system improved reproduction and thermal balance in dairy cows (Her et al., 1988; Mena Guerrero et al., 1993b; Wang et al., 1993) and maintained dairy performance in the summer almost at winter levels in moderate- to high-humidity Israel (Flamenbaum and Ezra, 2007). Mist-spraying did not improve thermal balance in similar environments (Mena-Guerrero et al., 1993a). Water contained in a hair coat 1 to $2 \mathrm{~mm}$ thick may require longer intervals for evaporation, justifying longer intervals between hair soaking (Berman, 2008). Forced evaporation from the hair coat extracted large amounts of heat from the body (Kimmel et al., 1992; Berman, 2008). Repeated cooling cycles may even shift thermal balance into a cold discomfort zone.

Evaporative cooling reduces ambient temperature, increases the surface to the ambient temperature gradient, and enhances the convective heat loss, allowing 
creation of an ambience compatible with maintenance of thermal comfort. Forced evaporation from the body surface does not modify ambient conditions, but instead relieves heat stress by extracting heat from the body surface. It is based on the presumption that peripheral vasodilation sustains near-maximal heat flow to the skin as long as hyperthermia persists. Such vasodilation would support heat extraction and, hence, heat stress relief. This report examined the distribution of surface temperature over the body of dairy cows during exposure to repeated cooling cycles to examine validity of this presumption.

\section{MATERIALS AND METHODS}

The study was carried out in May 1991 between 1100 to $1600 \mathrm{~h}$ on 4 individual Holstein cows of the Agricultural Research Organization dairy herd at Bet Dagan, Israel. The animals were in the shade of an open shed and tied in stanchions on a slatted floor. Ambient temperature during the measurements was $28^{\circ} \mathrm{C}$ $( \pm 0.1 \mathrm{SEM})$, the diurnal temperature amplitude was $13.3^{\circ} \mathrm{C}$, and relative humidity was $47 \%( \pm 0.2 \mathrm{SEM})$. A partial report of the results on 1 cow of this study was presented elsewhere (Kimmel et al., 1992).

Static garden sprinklers (model 943, NaanDan Jain Irrigation Systems, Post Naan, Israel) spraying 0.76 $\mathrm{m}^{3} / \mathrm{h}$ at $200 \mathrm{kPa}$ pressure were installed in the shed at a distance of $1.5 \mathrm{~m}$ apart, facing down from $1.5 \mathrm{~m}$ above the backs of the cows. The temperature of the water delivered ranged from 20 to $24^{\circ} \mathrm{C}$. Two fans (free flow, $12,200 \mathrm{~m}^{3} / \mathrm{h}$, model DDQ-632-6, Ziehl-Abegg, Kunzelsau, Germany) were mounted at a height of $3 \mathrm{~m}$ above the ground and produced airflow at velocities $>3 \mathrm{~m} / \mathrm{s}$ over the right side of the body surface. At this velocity, the evaporation rate from the hair coat was near maximal (Berman, 2008). In each case, following a 45-min control period in which the animals were exposed to the prevailing ambient conditions, the cows were cooled by repeated automatic sequential operation of the sprinklers for $30 \mathrm{~s}$ (while the fans were idle) followed by forced airflow for $4.5 \mathrm{~min}$. The cooling procedure was repeated for 9 to 15 cycles in the different replicates for a total of 45 to $75 \mathrm{~min}$. This procedure thoroughly wetted the hind part of the body (including hind legs), rump, and chest, but not the lower abdomen side, front legs, or neck. During this exposure, continuous infrared imaging of the right side of the body surface of the cows was carried out. Rectal temperatures were measured every 2 to 3 cooling cycles using a clinical thermometer inserted to a depth of $10 \mathrm{~cm}$ into the rectum.

The thermovision system consisted of an infrared camera (dynamic range $=10^{\circ} \mathrm{C}$; model 210 , Inframetrics, Burlington, VT) that converted the infrared radia- tion intensity coming from the viewed area to grayscale and recorded it as a video signal. Single frames were digitized by a frame grabber (ASUSTek Computer Inc., Fremont, CA) at 10 -s intervals, and frames $(\mathrm{n}=1,761)$ were stored. The gray intensity of the 8 selected areas (approximately $5 \times 20 \mathrm{~cm}$ ) was subsequently measured during the first 7 cooling cycles using Image J public domain software (http://rsb.info.nih.gov/ij/index.html). The 25 to $35^{\circ} \mathrm{C}$ gray scale was converted to temperature using an empirical regression based on the temperature range and optical density scale [i.e., temperature $\left({ }^{\circ} \mathrm{C}\right)=17.05+0.0715 \times$ density; $\left.\mathrm{R}^{2}=0.962\right]$. The temperature measured represented the radiant surface temperature $(\mathbf{T s})$ of the hair coat. The thickness of the hair coat on the sites was measured using a caliper and was 1 to $2 \mathrm{~mm}$ thick, a thickness range typical for Holstein dairy cows adapted to a warm climate (Berman, 2004). The Ts did not represent the temperature of the surface of the hair coat because the hairs did not create a continuous surface. Neither did Ts represent the temperature of the skin surface, because only little of it may be seen by the infrared camera. Rather, it represents the temperature of an intermediate layer of uncertain location in the skin-to-hair surface gradient. Because the hair coat thickness is 1 to $2 \mathrm{~mm}$, the skinto-surface temperature gradient may be assumed to be rather small.

The total number of Ts measurements on each body site ranged from 804 to 819 . The immediate responses to wetting were examined by data collected during the following periods: the last $1 \mathrm{~min}$ of the initial control period (i.e., before the hair coat was wetted), the first $0.5 \mathrm{~min}$ of the first cooling cycle (i.e., during the wetting of the coat), and the subsequent 1-min periods of the first cooling cycle. Data analysis was carried out by the GLM procedure of SAS (SAS Institute, Cary, NC), with Ts of the various sites as dependent variables and cow (as random term), period, and their interactions as independent variables. Significance of differences between periods was tested by contrast statements.

The immediate changes in Ts following wetting were estimated at 10-s intervals during the first cooling cycle following the first wetting. For this purpose, Ts data from 1 main body site and 2 body extremities sites that were wetted (rump, chest, upper and lower hind leg) were compared with similar sites $(\mathrm{n}=134)$ that remained dry (neck, abdomen, upper and lower front leg).

Changes in Ts during all cooling cycles were sorted into those belonging to the main body and those belonging to body extremities, with further sorting into sites that remained dry or were wetted during the procedure. This formed 4 classes of dependent data: main body wet (rump, chest) or dry (neck, abdomen) and 


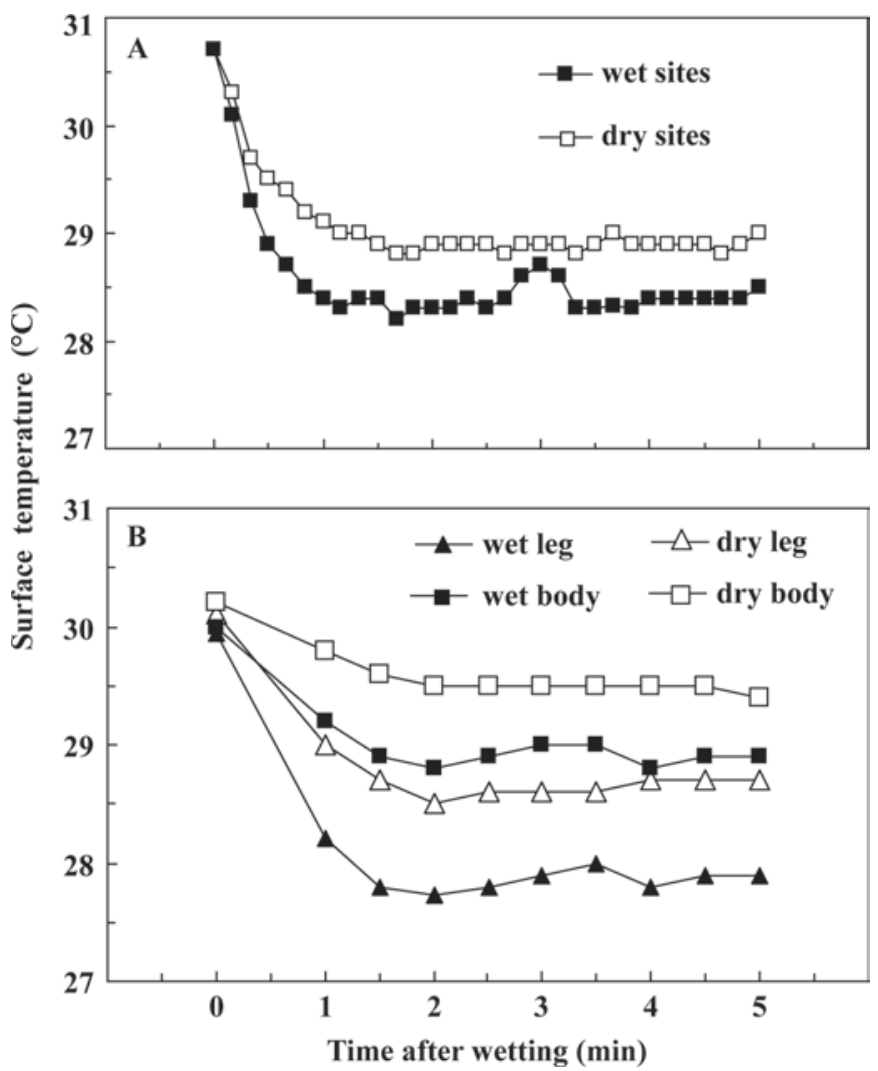

Figure 1. Mean changes in surface temperature $\left({ }^{\circ} \mathrm{C}\right)$ during the first cooling cycle in 4 cows, measured at 10-s intervals and averaged over 0.5-min periods. A) Changes in dry ( $\square$; neck, abdomen, and upper and lower front leg) and wetted ( $\mathbf{\square}$; rump, chest, and upper and lower hind leg) body sites. B) Mean changes in surface temperature in dry ( $\square$; neck, abdomen) and wetted ( $\mathbf{\square}$; rump, chest) main body sites and dry $(\Delta$; upper and lower front leg) and wetted ( $\mathbf{\Lambda}$; upper and lower hind leg) extremities. The SEM of all means was less than $0.1^{\circ} \mathrm{C}$.

extremity wet [upper and lower hind leg (above and below the hock, respectively)] or dry (upper and lower front leg; above and below the knee, respectively). The effects of the repeated cooling cycles were assessed by GLM analyses that included cow (as random term), cycle, time in cooling cycle, and their interactions as independent variables.

\section{RESULTS}

\section{Immediate Effects}

Surface temperatures in the first cooling cycle were altered by less than $0.1^{\circ} \mathrm{C}$ by deletion of the first 30 to $40 \mathrm{~s}$ during which wetting occurred. This indicates that immediate, direct cooling of hair coat by water had little effect on Ts. Following wetting, Ts decreased rapidly in the wetted sites (Figure 1A). The Ts reached minimum values approximately $1 \mathrm{~min}$ following wetting. A similar change, albeit smaller and slower to take place, occurred in the sites that remained dry during the procedure. The Ts of dry and wet body sites was practically identical at the start of the first cooling cycle. The mean difference in Ts between dry and wet sites in the period of min 2 to 5 after the first wetting was $0.5^{\circ} \mathrm{C}( \pm 0.02 \mathrm{SEM})$.

It was of interest to examine the changes in Ts in the dry and wet main body and body extremities during the first cooling cycle (Figure 1B). The decrease in Ts following wetting was of similar duration in both main body and extremities, but the decrease was larger $(P$ $<0.01)$ in the legs than in the main body and was larger in wet sites than in dry sites $(P<0.01)$. In all body sites, a plateau in Ts was reached by min 2 after wetting. Mean Ts values for the period of min 2 to 5 after wetting when surface temperatures were stable were $-2.2 \pm 0.09^{\circ} \mathrm{C},-1.5 \pm 0.07^{\circ} \mathrm{C},-1.2 \pm 0.03^{\circ} \mathrm{C}$, and $-0.6 \pm 0.01^{\circ} \mathrm{C}$ for the wet leg, dry leg, wet main body, and dry main body, respectively $(P<0.01)$.

The effect of 7 consecutive cooling cycles on changes in Ts was examined after excluding the Ts measured during the first $50 \mathrm{~s}$ of each cooling cycle to avoid transient effects of wetting (Figures $2 \mathrm{~A}$ and $2 \mathrm{~B}$ ). The mean Ts of the different body areas decreased over the course of consecutive cooling cycles, during which they seemed to reach a plateau. Following 2 cooling cycles, the difference between upper and lower leg parts was more than 2-fold larger in the hind leg than in the front leg (data not shown). The dry leg sites reached a plateau in the third cooling cycle, similarly to the dry main body sites. This contrasted with the wetted body sites: a plateau was reached by 5 cooling cycles for the wetted leg sites, whereas the decrease seemed to continue beyond 7 cooling cycles for the wet main body sites. The Ts reached by 5 and 7 cooling cycles probably represents an estimate of Ts reached by the end of 7 consecutive cooling cycles of 5 min each, repeated over approximately $35 \mathrm{~min}$. Mean Ts, averaged for the fifth and seventh cooling cycles for the wetted leg, dry leg, wetted main body, and dry main body, were 25.9, $27.1,26.3$, and $28.1^{\circ} \mathrm{C}$, respectively, with the standard error of the mean ranging from 0.01 to 0.02 . The difference between wetted and dry legs was smaller than that between wetted and dry main body $\left(1.2\right.$ vs. $1.8^{\circ} \mathrm{C}$, respectively).

It remains unclear whether consecutive cooling cycles alter the time course of Ts during the cooling cycle. This was examined separately for the main body and extremities and for wetted and dry areas (Figure 3). The Ts changed during the cooling the cycle only in min 1 of the first cooling cycle. This was true for the main body, dry or wetted, as well as for the legs, regardless of whether these sites were dry or wetted. The repetition of cooling at 5 -min intervals for 5 to 7 cycles reduced mean Ts. The most definite effect of recurring 


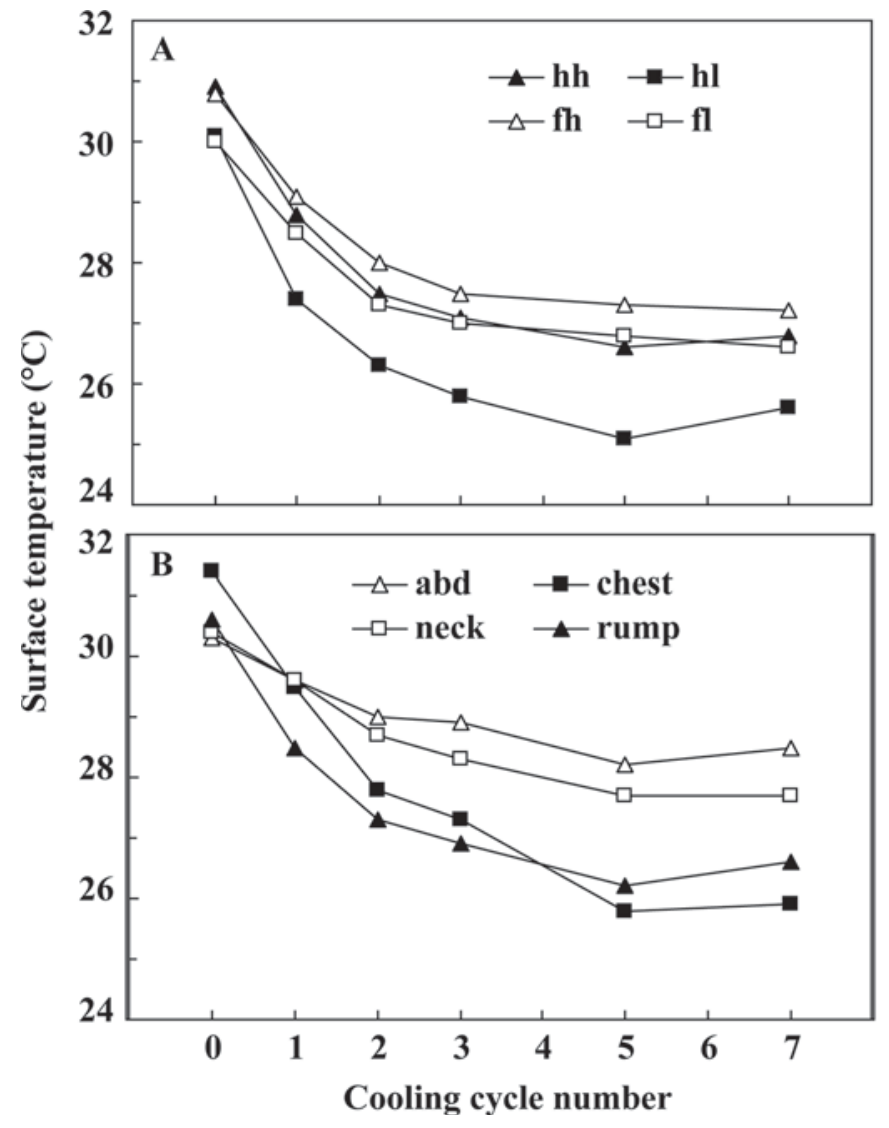

Figure 2. Mean surface temperature $\left({ }^{\circ} \mathrm{C}\right)$ averages of 4 cows during the period of min 1 to 5 after wetting by cooling cycles. A) Averages of upper and lower sites on hind ( $\mathrm{hh}=$ high hind; hl = low hind) and front $(\mathrm{fh}=$ high front; $\mathrm{fl}=$ low front) legs. B) Averages of main body (abdomen side, neck, chest, and rump). Open symbols represent dry sites; closed symbols represent wetted sites. The SEM of all means was less than $0.1^{\circ} \mathrm{C}$.

cooling cycles was on the wetted main body sites, in which Ts were distinctly reduced in the fifth cooling cycle and thereafter.

\section{Cumulative Effects of 7 Cooling Cycles}

Initial rectal temperatures ranged from 38.8 to $39.0^{\circ} \mathrm{C}$ and remained unchanged during the first 5 cooling cycles, with a $0.1^{\circ} \mathrm{C}$ reduction observed between the seventh to eighth cooling cycles. It was only after 8 to 10 cooling cycles that rectal temperature decreased to reach $38.4^{\circ} \mathrm{C}( \pm 0.06 \mathrm{SEM})$ with no further reduction in temperature, even after 18 cooling cycles in one extreme case.

The mean Ts for the 7 body locations during the initial control period and during the seventh cooling cycle, and the difference between them, is shown in Table 1. The standard error of the mean was $0.1^{\circ} \mathrm{C}$ in all cases. During the initial control period, mean Ts on the sites examined ranged from 30.0 to $31.2^{\circ} \mathrm{C}$, a $1.2^{\circ} \mathrm{C}$ range. During this period, the highest Ts was recorded on the chest. During the seventh cooling period, mean Ts on the same sites ranged from 25.6 to $27.9^{\circ} \mathrm{C}$, a $2.3^{\circ} \mathrm{C}$ range. At this stage, among the sites wetted (rump, chest, and hind leg), mean Ts ranged from 25.6 to $26.7^{\circ} \mathrm{C}$, a $1.1^{\circ} \mathrm{C}$ range. The highest mean Ts at this stage $\left(28.5\right.$ and $\left.27.9^{\circ} \mathrm{C}\right)$ were on abdomen side and neck, sites that were not wetted by this procedure. The reduction in mean Ts produced by 7 wetting and forced ventilation cycles was 4.0 to $6.0^{\circ} \mathrm{C}$ in the wetted areas. A smaller reduction, 1.6 to $3.7^{\circ} \mathrm{C}$, occurred in the sites that were not wetted.

Chest surface temperature was the highest initially, but it was the site in which the greatest reduction in temperature occurred during cooling. It decreased from $31.2^{\circ} \mathrm{C}( \pm 0.1 \mathrm{SEM})$ to $25.9^{\circ} \mathrm{C}( \pm 0.1 \mathrm{SEM})$ with recurring cooling cycles, a reduction of $5.3^{\circ} \mathrm{C}$ over 7 cooling cycles. The decrease in Ts between the first and seventh cooling cycles ranged from 1.1 to $2.0^{\circ} \mathrm{C}$ for other body sites. The patterns of rump and chest temperatures were similar to each other, as were those of the abdomen and neck. Rump and chest differed from neck and abdomen in the larger change in surface temperatures during cooling ( 4.3 vs. $2.4^{\circ} \mathrm{C}$, respectively; $\pm 0.1 \mathrm{SEM}$ ). In both rump and chest, there was a gradual reduction in temperature during 3 cooling cycles, following which temperatures reached a plateau. In the neck and abdomen, the changes in temperature were markedly smaller (3.5 vs. $1.8^{\circ} \mathrm{C}$, respectively; $\left.\pm 0.1 \mathrm{SEM}\right)$.

The Ts reached by legs was the lowest $\left(25.1^{\circ} \mathrm{C} ; \pm 0.1\right.$ SEM) for the lower hind leg. The Ts of the upper hind leg and of the upper and lower front legs were similar to each other $\left(26.8,27.4\right.$, and $27.0^{\circ} \mathrm{C}$, respectively; \pm 0.1 SEM for all means). The Ts reached by the lower hind leg was similar to that reached by the rump and chest. The pattern of temperature changes on the rump and chest differed from that of the other sites: the former was close to linear, whereas the latter shared a curvilinear pattern. The patterns of temperature change in the hind leg and front leg were alike, although the former was wetted and the latter was not.

\section{DISCUSSION}

In this study, a cooling procedure (Flamenbaum et al., 1986) that consisted of periods of $30 \mathrm{~s}$ of wetting and $4.5 \mathrm{~min}$ of forced ventilation was repeated at 5 -min intervals for $35 \mathrm{~min}$ or more. Forced evaporation is a powerful means for extracting heat from the body periphery. The initial application of water in the first cooling cycle affected surface temperature on the hind and front leg after 0.5 to $1 \mathrm{~min}$. The temperature of the hair coat surface in shaded animals, as in this study, 
Table 1. Mean surface temperature $\left({ }^{\circ} \mathrm{C}\right)$ of 4 cows measured at 10 -s intervals during the initial control period and during the seventh cycle of cooling $^{1}$

\begin{tabular}{|c|c|c|c|c|c|c|c|c|}
\hline Item & Abdomen side & Rump & Chest & Neck & \multicolumn{4}{|c|}{ Leg } \\
\hline Control period & 30.1 & 30.6 & 31.2 & 30.4 & 30.7 & 30.0 & 30.3 & 30.2 \\
\hline Difference $^{2}$ & 1.6 & 6.0 & 5.3 & 2.5 & 4.0 & 4.4 & 3.1 & 3.7 \\
\hline Wetting & No & Yes & Yes & No & Yes & Yes & No & No \\
\hline
\end{tabular}

${ }^{1}$ The SEM was $0.1^{\circ} \mathrm{C}$ in all cases.

${ }^{2}$ All differences between the initial control period and seventh cooling cycle were statistically significant $(P<0.05)$.

depends upon the difference between heat flowing from the body core to the skin and between that flowing from the hair surface to the atmosphere. The reduction in Ts occurred on the wetted hind leg as well as on the dry front leg, and it most likely reflects not only the extraction of heat from the body periphery but also a vasoconstrictor response and a concomitant restriction of heat flow to the skin surface (Johnson et al., 1976). It is significant that such response was not observed on the chest and rump (the latter not shown in Figure 1 ), probably because of the different surface:mass ratio on these areas, which may have masked the immediate vasomotor response. The reduction in surface temperature described here implies that loss of heat from the hair coat is larger than the influx of heat into it from the skin.

The approach to Ts in heat balance models is equivocal. In one model of skin heat loss, a constant heat flow to skin was assumed because constant body temperature and core-to-skin heat conductance values were presumed (Gebremedhin and $\mathrm{Wu}, 2001$ ). In another model, heat flow to skin was presumed to vary passively with thermal balance (McGovern and Bruce, 2000). In both models, Ts was presumed uniform over the entire body surface. In either view, changes in Ts reflected a passive involvement in thermal balance rather than playing an active role in it, as consistent with concepts of thermoregulation (Bligh, 1998). Neither view contemplated a controlled reduction in heat flow to skin that would lead to a decrease in Ts.

The loss of heat by forced evaporation from the hair coat depends on its water content. A reduction in hair coat water content leads to decreasing evaporation and, hence, to a rise in hair coat temperature until its water content is exhausted. The time required for this, as estimated from Berman (2008), was highly dependent upon airflow. At an air velocity of $\leq 0.5 \mathrm{~m} / \mathrm{s}$, the Ts of the wetted surface was close to that of the dry one, indicating that rate of heat extraction was smaller than the rate of heat flow from the skin. The wetted surface temperature reached $95 \%$ of the dry hair surface temperature by 8 and $11 \mathrm{~min}$ after wetting at air veloci- ties of 1 and $2 \mathrm{~m} / \mathrm{s}$, respectively (Dolejs et al., 2000). Therefore, the responses observed in this study most likely reflect an evaporation rate not limited by hair coat water content. A reduction in Ts may result in not only forced evaporation but also vasomotor changes that would restrict heat transfer from body core to body surface. That such changes were present may be
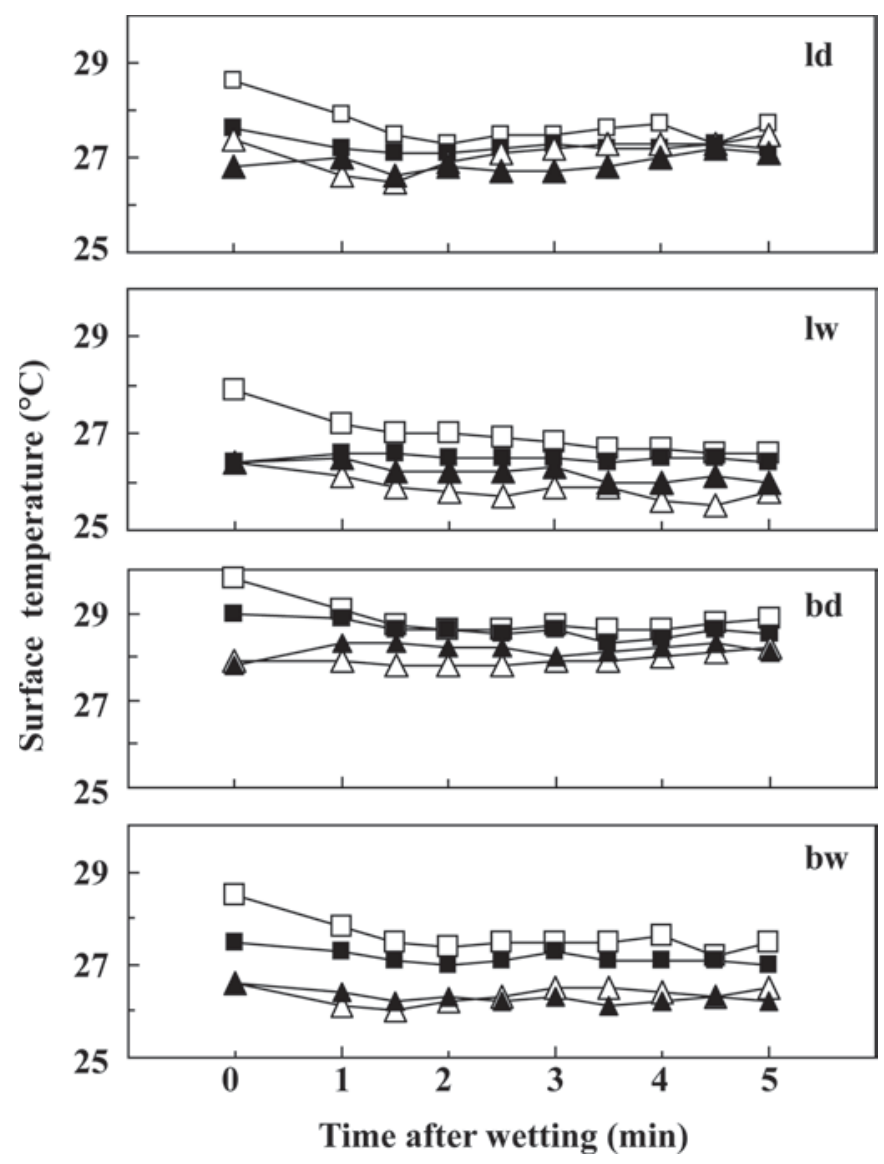

Figure 3. Time course of surface temperature $\left({ }^{\circ} \mathrm{C}\right)$ averages for 0.5 min periods during the second $(\square)$, third $(\mathbf{\square})$, fifth $(\Delta)$, and seventh (ム) cycles of 7 consecutive cooling cycles in 4 cows. ld = dry leg; lw = wetted leg; bd = dry main body (neck, abdomen); bw = wetted main body (rump, chest). The SEM of all means was less than $0.1^{\circ} \mathrm{C}$. 
inferred from the decreases in Ts in areas that were not wetted by the procedure.

The decrease in Ts was the greatest following the first cooling cycle. Subsequent decreases were smaller: following the second and third cycles, they were 35 and $23 \%$ of the initial decrease, respectively. The decrease in Ts following the first cooling cycle was larger on the wetted sites than on the dry body sites $\left(2.2\right.$ vs. $1.2^{\circ} \mathrm{C}$, respectively) and did not markedly differ between them after subsequent cooling cycles. A decrease in Ts reduces convective heat loss because the latter is proportional to the gradient between surface and ambient temperatures. If $\mathrm{Ts}$ decreases below ambient temperature, convective heat exchange may be reversed and heat may be gained from the ambient air. A decrease in Ts below ambient temperature counteracts the capacity of forced evaporation for relief of heat stress. Evaporative heat loss was little affected by the surface-to-ambient temperature gradient and was enhanced by forced ventilation (Gebremedhin and $\mathrm{Wu}, 2001$ ).

Rectal temperature was almost constant at $38.9^{\circ} \mathrm{C}$ during the first 5 cooling cycles, with a reduction of only $0.1^{\circ} \mathrm{C}$ in the seventh cooling cycle. Flow of metabolic heat from body core to skin is determined by tissue heat conductance. In a study by Berman (2004), tissue conductance in cows adapted to subtropical summer and winter was estimated as 21 and $14.6 \mathrm{~W} / \mathrm{m}^{2}$, respectively, compared with the 7.3 minimal conductance in cows adapted to cold. Flow of heat from skin to air depends on heat conductance from skin to hair surface and from hair surface to air. The hair coat of the cows in this study was at most $2 \mathrm{~mm}$ thick. In such a coat, when saturated with water, skin temperature was close to surface temperature (Berman, 2008). Because hair coat heat conductance is practically constant over short periods, changes in Ts reflect changes in heat flow from core to skin. Heat conductance from hair coat to air (i.e., boundary layer conductance) was affected by air velocity; at $1.5 \mathrm{~m} / \mathrm{s}$ it was $18.1 \mathrm{Kcal} \cdot \mathrm{m}^{2} \cdot \mathrm{h} /{ }^{\circ} \mathrm{C}$ of the skin surface-to-air temperature gradient (Berman, 2004). The decrease in Ts thus reduced convective heat loss.

The cooling procedure reduced Ts and, because both core temperature and the surface-to-air heat conductance remained constant, this reduction in Ts implied a reduction in tissue heat conductance. Had the decrease in Ts occurred on wetted areas only, it could be interpreted as indicating that loss of heat by forced evaporation was greater than heat conveyed to the body surface. But the reduction in Ts was not limited to the cooled areas and it extended to areas not wetted. A decrease in Ts that occurred in areas that were not wetted supported Brouk et al. (2003), suggesting the involvement of a vasomotor response that reduced blood flow and heat influx to the surface. This reduction in peripheral blood flow occurred when initial body temperature was $39.0^{\circ} \mathrm{C}$ in the present study, as well as when it was $39.5^{\circ} \mathrm{C}$ (Brouk et al., 2003). These findings point to complex effects of body surface cooling: on one hand, an initial increase in core temperature of variable magnitude, and, on the other hand, an extraction of heat from the body periphery that leads to the creation of a cooled superficial body layer. The depth of this layer would increase with duration of heat extraction, as indicated by the decrease in Ts in successive cooling cycles. This body layer tentatively forms a peripheral heat sink, which ultimately reduces body core temperature by heat flow from the body core to its periphery.

In other studies, a decrease in body core temperature following an initial rise occurred after 30 to $40 \mathrm{~min}$ of recurring cooling cycles (Brouk et al., 2003). Rectal temperature decreased for $1 \mathrm{~h}$ or more after the end of cooling in another study of repeated cooling cycles (Flamenbaum et al., 1986). In the present study, a decrease in rectal temperatures was observed in cases in which cooling cycles recurred for approximately $1 \mathrm{~h}$. An effect of initial core temperature levels on the pattern of response is equivocal because initial core temperatures as well as response patterns were different in this and the other studies cited. Limited information is available on the factors affecting the time course of vasomotor and core temperature during peripheral cooling.

These data, taken collectively, suggest that it is difficult, if not improbable, to assess the expected benefit of surface cooling from immediate core temperature changes. The continued decrease in surface temperature most likely represents a gradual increase in the thickness of the cooled peripheral body layer. The slow and delayed transfer of heat from the body core to the cooler body peripheral shell produces the desired reduction in body temperature.

Presently, heat stress relief is conceived as restoration of normothermic core temperature. The common routine for cooling the body periphery leads to an initial increase in core temperature later followed by an outflow of heat from the core to the surface. The restoration of normothermic core temperature depends upon the heat conductance from body core to skin. Reducing the intensity of peripheral vasoconstriction (i.e., increasing heat conductance from body core to skin) may enhance the restoration of normothermic core temperature and reduce the prevalence of hyperthermic peaks. This may be attained by increasing intervals between cooling cycles as well as by reducing rate of heat extraction (e.g., by lower airflow velocity or 
lesser wetting). A study of the vasoconstrictor response to peripheral cooling is needed to further advance heat stress relief methods.

\section{REFERENCES}

Armstrong, D. V., F. Wiersma, T. J. Fuhrmann, J. M. Tappan, and S. M. Cramer. 1985. Effect of evaporative cooling under a corral shade on reproduction and milk production in a hot-arid climate. J. Dairy Sci. 68:167-168.

Berman, A. 2004. Tissue and external insulation estimates and their effects on prediction of energy requirements and of heat stress. J. Dairy Sci. 87:1400-1412.

Berman, A. 2006. Extending the potential of evaporative cooling for heat-stress relief. J. Dairy Sci. 89:3817-3825.

Berman, A. 2008. Increasing heat stress relief produced by coupled coat wetting and forced ventilation. J. Dairy Sci. 91:4571-4578.

Berman, A. 2009. Predicted limits for evaporative cooling in heat stress relief of cattle in warm conditions. J. Anim. Sci. 87:3413-3417.

Bligh, J. 1998. Mammalian homeothermy: An integrative thesis. J. Therm. Biol. 23:143-258.

Brouk, M. J., J. F. Smith, and J. P. Harner. 2003. Effect of sprinkling frequency and airflow on respiration rate, body surface temperature and body temperature of heat stressed dairy cattle. Pages 263-268 in Proceedings of the Fifth International Dairy Housing Conference, Fort Worth, TX. ASABE, St. Joseph, MI.

Brown, W. H., J. W. Fuquay, W. H. McGee, and S. S. Iyengar. 1974. Evaporative cooling for Mississippi dairy cows. Trans. ASAE $17: 513-515$.

Dolejs, J., O. Toufar, and J. Knizek. 2000. Evaporative cooling of cows in a non-homogeneous temperature field. Czech J. Anim. Sci. $45: 75-80$.

Flamenbaum, I., A. Berman, and D. Wolfenson. 1984. Summer effect on milk production and conception rate of high yielding dairy cows in Israel and its alleviation. Page 2 in Proc. 35th Ann. Meeting
European Federation of Animal Science (EAAP), The Hague, the Netherlands. EAAP, Rome, Italy.

Flamenbaum, I., and E. Ezra. 2007. Effect of level of production and intensive cooling in summer on productive and reproductive performance of high yielding dairy cows. J. Dairy Sci. 90(Suppl. 1):231. (Abstr.)

Flamenbaum, I., D. Wolfenson, M. Mamen, and A. Berman. 1986 Cooling dairy cattle by a combination of sprinkling and forced ventilation and its implementation in the shelter system. J. Dairy Sci. 69:3140-3147.

Gebremedhin, K. G., and B. Wu. 2001. A model of evaporative cooling of wet skin surface and fur layer. J. Therm. Biol. 26:537-545.

Her, E., D. Wolfenson, I. Flamenbaum, Y. Folman, M. Kaim, and A. Berman. 1988. Thermal, productive, and reproductive responses of high yielding cows exposed to short-term cooling in summer. J. Dairy Sci. 71:1085-1092.

Johnson, J. M., G. L. Brengelmann, and L. B. Rowell. 1976. Interactions between local and reflex influences on human forearm skin blood flow. J. Appl. Physiol. 41:826-831.

Kimmel, E., H. Arkin, and A. Berman. 1992. Evaporative cooling of cattle: Transport phenomena and thermovision. Paper 924028, Int. Summer Meeting American Society of Agricultural and Biological Engineers (ASAE), Charlotte, NC. ASAE, St. Joseph, MI.

McGovern, R. R., and J. M. Bruce. 2000. A model of the thermal balance for cattle in hot conditions. J. Agric. Eng. Res. 77:9192.

Mena-Guerrero, Y., A. Gomez-Cabrera, and J. M. Serradilla-Manrique. 1993a. The use of mist-spraying to relieve heat stress in dairy cows. Arch. Zootec. 42:179-182.

Mena Guerrero, Y., A. Gomez Cabrera, and J. M. Serradilla Manrique. 1993b. Alleviation of heat stress in dairy cows: Sprinkling plus aeration. Arch. Zootec. 42:89-92.

Wang, J. W., S. Y. Lu, Y. C. Hu, and T. W. Yang. 1993. Effects of evaporative cooling on lactation and reproduction of Holstein cows in summer. J. Chin. Soc. Anim. Sci. 22:163-173. 